\title{
STUDY OF NOISE POLLUTION DUE TO THE SOUND AMPLIFIERS:- CASE STUDY COMPARISON BETWEEN LOCAL AND MODERN MARKET IN DIWANEYAH CITY
}

\author{
Mukhtar DH. Abbas, \\ Ministry Of Environment, Al-Qadissiyah Environment Directorate, AL-Diwaneyah - Iraq. \\ E-mail: shubarmuktar@yahoo.com \\ Mukhlis H. Mojid, \\ Ministry Of Environment, Al-Qadissiyah Environment Directorate, AL-Diwaneyah - Iraq. \\ E-mail: muklis06@yahoo.com \\ Hiba A. Majeed, \\ Ministry Of Environment, Al-Qadissiyah Environment Directorate, AL-Diwaneyah - Iraq. \\ E-mail: hibasalam@outlook.com
}

Received on 12 November 2017 Accepted on 13 December 2017 Published on 15 March 2018 DOI: $10.30772 / q j e s . v 10 i 4.507$

\begin{abstract}
The objective of this study is to identify the effect of the noise that result from sound amplifiers which have been used in Local markets on the healthy and psychology of population (vendors and pedestrian). Therefore, we measured the noise level in Local and Modern markets to identify the difference in noise level that create by sound amplifiers where we chose three points in each market at (North, Mid and South) and for a period of seven days and comparison the readings of noise level of both markets with the Iraqi standard. two questionnaires have been carried out in this study, the firs questionnaire is for the vendors. The second questionnaire represents the pedestrians.For a period of seven days, the average of the noise levels (Leq) in Local market for North, Mid and South points were (77.2, 80.2 and 73.4) decibel $(\mathrm{dB})$ respectively while in the Modern market were $(66.2,69.1$ and 64.8) $\mathrm{dB}$ respectively. The results of the first questionnaire showed that the vendors in Local marked are more harmful than the ones in the Modern market where most of them suffered from hear losing, annoying, boredom, mood flocculation, weakness of focus and other psychological effects but the harm ratio with hypertension was low in both markets. The results of the second questionnaire showed that the harm ratio of shoppers in Local and Modern markets with annoying equal to $(92 \%, 17 \%)$, headache $(58 \%, 25 \%)$, nervous $(25 \%, 25 \%)$, boredom $(33 \%, 25 \%)$, Weakness of focus $(58 \%, 42 \%)$, nausea $(67 \%, 58 \%)$, respectively. These results give an impression that the sound amplifiers were the essential reason for increasing the noise level in local markets and the noise level higher than $70 \mathrm{~dB}$ cause healthy and psychological effects for the vendors.
\end{abstract}

Keywords: - Noise, Sound Amplifiers, Local market, Modern market. 


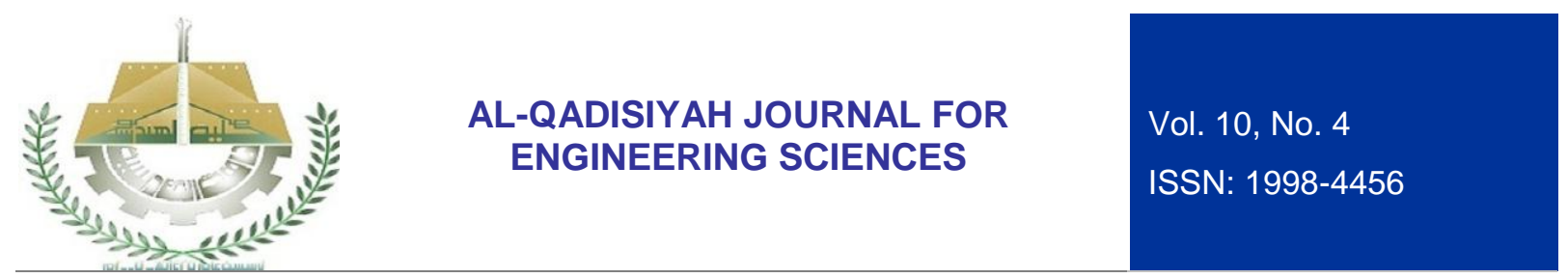

\section{INTRODUCTION}

Noise pollution in cities has become a global concern because its seriousness and its problems to many activities such as transportation, commercial, industrial and constructional works. Every nation concerns about the health effects of noise emitted from the expanding number of vehicles moving on the roads. [1]. The major source of noise in outdoor environment such commercial district is the transportation system such as taxies. However, at the local markets in diwaneyah city, the sound amplifiers are the hazard source of the noise where the vendors have used these devices as part of advertising about their goods. These sound amplifiers cause high levels of noise which they have been adversed impact on the population.

In general, there are two categories of biologic impact that cause noise : auditory (hearing loss) and non-auditory effects such as annoying, sleep disorder, hypertension, impair cognation and effect outcome). [2]. Noise pollution is a most important occupational hazard, temporary impact of noise exposure includes hearing loss, annoyance. permanent health impact of noise exposure results in hearing loss; both temporary and permanent impact can be avoided by timely recognition, assessment and control of noise pollution. [3]. Many studies have been conducted about the healthy impact of the noise on the population. The most serious health impact is hearing loss which is resulting from permanent harm to the inner ear. [4].

Generally, Body pain and head ache were the most common health symptoms among people who were exposed to noise pollution. Noise affects blood pressure regardless of gender and age of the individual.[5]. Exposure to high levels of noise can affected humans, such as hypertension, psychological symptoms and vasoconstriction disease. [6]. The continuous exposure to the noise increases hypertension of male workers independently.[7]. The continuous exposure to levels of noise range (52.52 to 65.74) Decibel causes a rise of hypertension and pulse rate [8]. Many researchers have studied and evaluate the noise pollution in Iraq and from them Hussein Janna who studied the effect of noise pollution on the schools and health centers in Diwaneyah city [9].Therefore, the objectives of this study were to measure the level of the noise and identify its impact on the population specially the vendors in the local Market and compare it with Modern market and finding the engineering solution to mitigate the noise.

\section{AREA OF STUDY}

Al- Diwaneyah city placed in the middle of Iraq (about $180 \mathrm{~km}$ south of Baghdad) where the population is about $(403,726)$ persons.

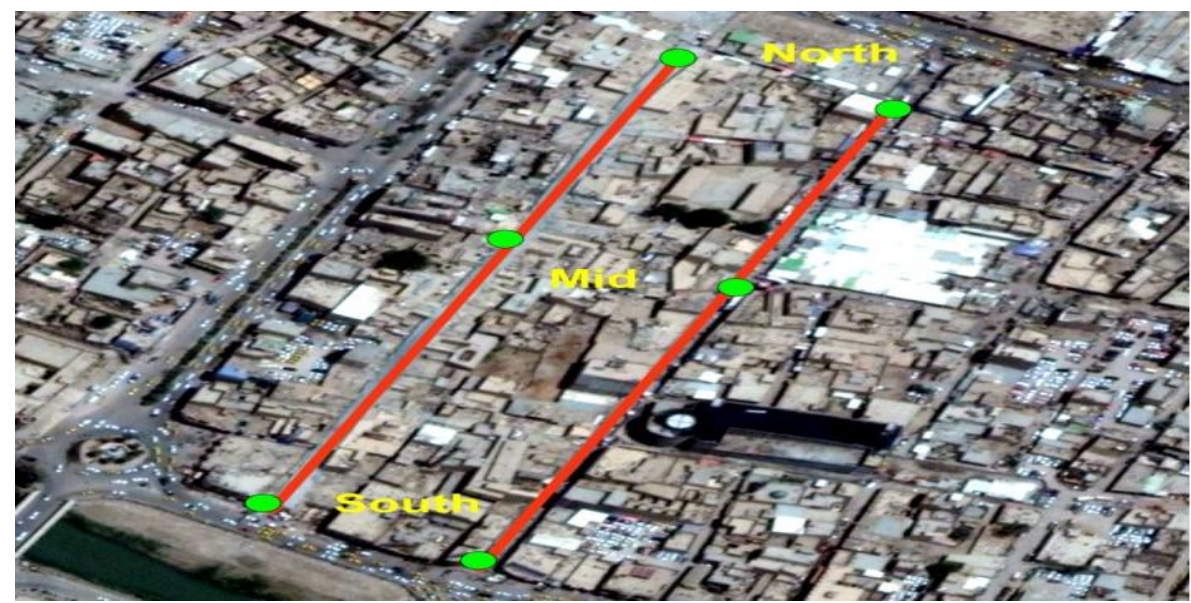

Figure 1: picture show the places of the Local and Modern markets. 
The study area was commercial where we choose the largest two markets in this city, one of them is Local in which the sound amplifiers have been used and compare it to the Modern market where the sound amplifiers have not been used. These markets have same engineering properties length, almost 500 meter, width, number of shops and almost the same goods as shown in the Figure (1).

\section{MATERIALS AND METHOD}

This study included three parts of work, the first part was measuring the level of the noise in two places Local and Modern markets with three points: North, Mid and South in each one of the markets for a period of seven days and the period of each measure which was a quarter hour, then compare it together and with Iraqi standard NO. (41) 2015. The measure of the noise by using sound meter (SVAN 955) with 1.2meter-high and the side distance from any neighboring obstacle more than one meter. The second part includes questionnaire which specialized for the venders in both markets who remain in their work from ( 6 $10)$ hours per day. The number of respondents were fifty (50) in each market with (13) questions about the psychological and healthy impact which included (hear losing, hypertension, annoying, headache, nervous, boredom, control and performance, nausea, mood fluctuation, sleep disorder and the desire to quarrel with client or neighboring). The last part using questionnaire specialized for 12 persons stayed for a period of two hours only in the first day in Local market and repeat the same questionnaire with Modern market for the same persons to determine the noise level impact on the shoppers.

\section{RESULTS}

In this study, the researchers measure the noise level at three points (North, Mid and South) in each market (Local and Modern) for a period of seven days, The readings of noise levels (Leq) at Local market were as followed, in North the noise level was (73.7 to 81) dB with average of $77.2 \mathrm{~dB}$ and Stdev 2.54. , in Mid market the noise level was (74.1 to 85.6) dB with average of $80.2 \mathrm{~dB}$ and Stdev 3.25 and in South was the noise level ranged ( 70.5 to 76 ) decibel $(\mathrm{dB})$ with average of $73.4 \mathrm{~dB}$ and the standard deviation (stdev) of 1.86 .

In the North of Modern market, the readings of noise level (Leq) was (63.2 to 68.1) dB with average $66.2 \mathrm{~dB}$ and Stdev 1.91, in the Mid market, it was (66.6 to 74.5) dB with average $69.1 \mathrm{~dB}$ and Stdev 2.6 and in South, it was ranged (62.6 to 67) dB with average $64.8 \mathrm{~dB}$ and the standard deviation (stdev) 1.48 . Figures 2,3 and 4 and table (1) show the above results. 


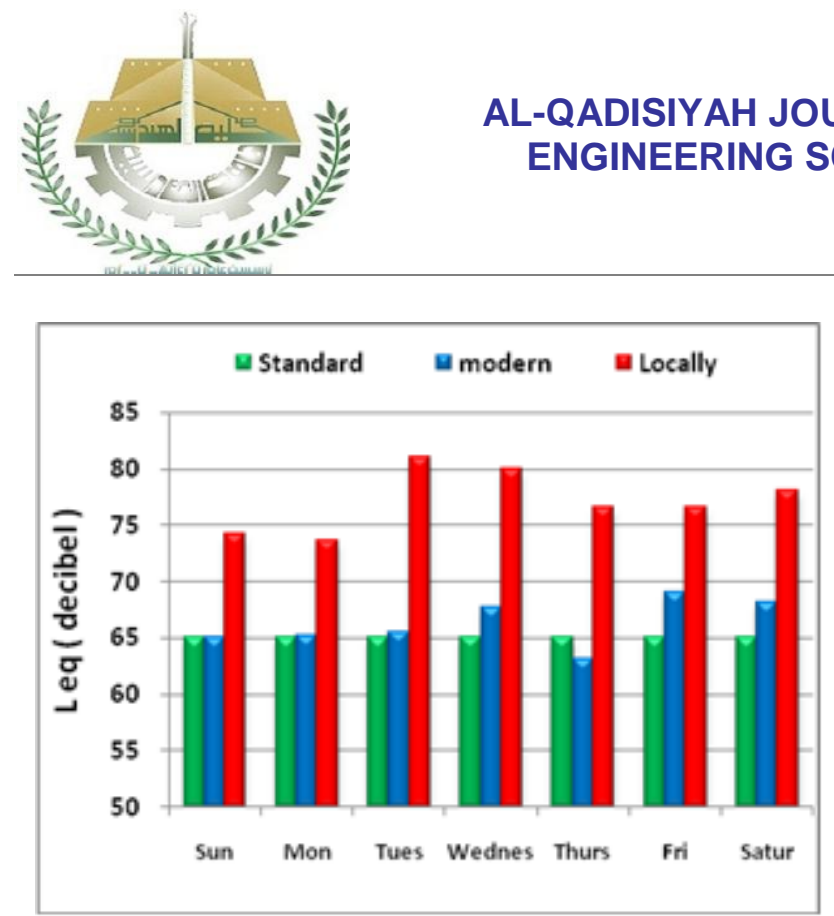

Figure 2: The noise levels in (Leq) in North.

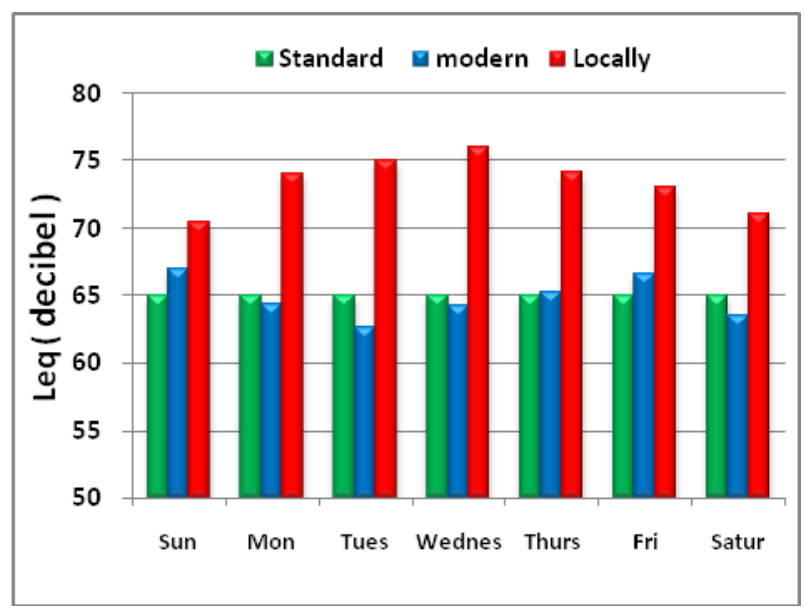

Figure 4: The Noise Levels In (Leq) In South.

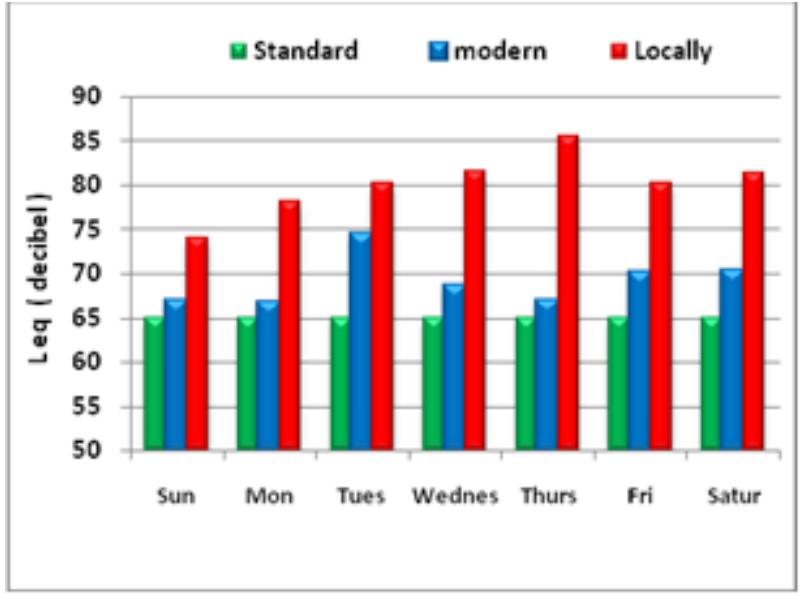

Figure 3: The noise levels in (Leq) in Mid.

Table 1: The readings of noise level in (Leq) $\mathrm{dB}$.

\begin{tabular}{|c|c|c|c|c|c|c|}
\hline \multicolumn{6}{|c|}{ Leq } & \multirow{3}{*}{ Days } \\
\hline \multicolumn{3}{|c|}{ Modern market } & \multicolumn{3}{|c|}{ Local market } & \\
\hline South & Mid & North & South & Mid & North & \\
\hline 67.0 & 66.9 & 65 & 70.5 & 74.1 & 74.2 & Sun \\
\hline 64.4 & 66.6 & 65.2 & 74 & 78.2 & 73.7 & Mon \\
\hline 62.6 & 74.5 & 65.5 & 75 & 80.2 & 81 & Tues \\
\hline 64.3 & 68.6 & 67.7 & 76 & 81.6 & 80 & Wed \\
\hline 65.3 & 66.9 & 63.2 & 74.2 & 85.6 & 76.6 & Thurs \\
\hline 66.6 & 70 & 69 & 73 & 80.3 & 76.6 & Fri \\
\hline 63.5 & 70.2 & 68.1 & 71.1 & 81.4 & 78.1 & Sat. \\
\hline
\end{tabular}

The readings of Maximum noise level at Local market were as following, in North, it was (92.2 to 102.2) $\mathrm{dB}$ with average of $97.9 \mathrm{~dB}$ and Stdev of 4.01. , in Mid market, it was (86.5 to 98.6) dB with average of $93.1 \mathrm{~dB}$ and Stdev of 3.72 and in South was, it ranged (86.7 to 98.1) dB with average of $91.2 \mathrm{~dB}$ and the standard deviation (stdev) of 3.43. In Modern market, the readings of noise level (MAX.), in North, it was (80.4 to 89.6) dB with average of $85.3 \mathrm{~dB}$ and Stdev of 3.27, in the Mid market, it was (83.2 to 93.7) dB with average of $89 \mathrm{~dB}$ and Stdev. of 3.97 and in South, it ranged (76.4 to 82.7) dB with average of $81.4 \mathrm{~dB}$ and the standard deviation (stdev) of 3.29. Table (2) shows the result of maximum noise level in Local and modern markets.

The readings of Minimum noise level at Local market were as following, in North, it was (60.4 to 63.4) $\mathrm{dB}$ with average of $62.3 \mathrm{~dB}$ and Stdev. of 0.96 , in Mid market, it was (63.4 to 71.3) $\mathrm{dB}$ with average of 68.3 $\mathrm{dB}$ and Stdev. of 2.94, and in South, it ranged (58.5 to 63.8) dB with average of $91.2 \mathrm{~dB}$ and the standard deviation (stdev) 3.43. In Modern market, the readings of noise level (Min.), in North was (55.1 to 58.4) dB with average of $56.7 \mathrm{~dB}$ and Stdev. of 1.28, in the Mid market, it was (55.2 to 58.4) dB with average of 56.4 $\mathrm{dB}$ and Stdev. of 1.17 and in South, it ranged (55.2 to 57.7) dB with average of $56.6 \mathrm{~dB}$ and the standard deviation (stdev) of 0.88. Figures 5,6 and 7 and table (2) show the above results. 


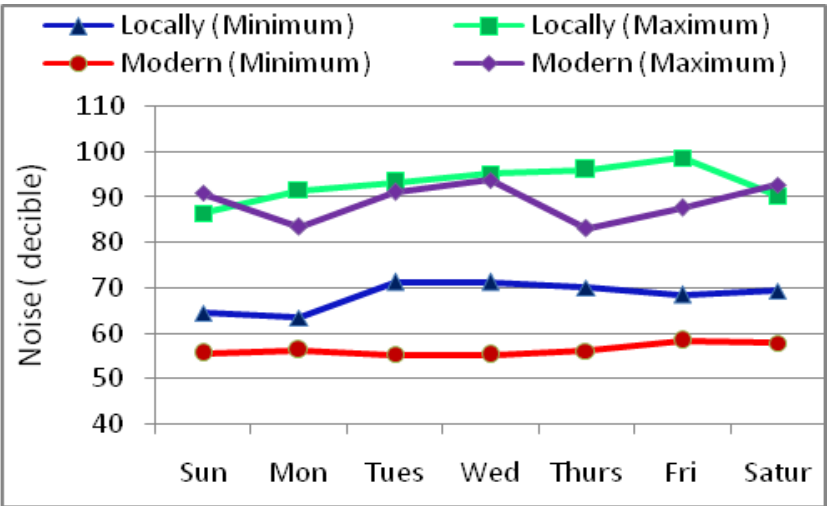

Figure 5: The Noise Levels (Max. and Min.) In South.

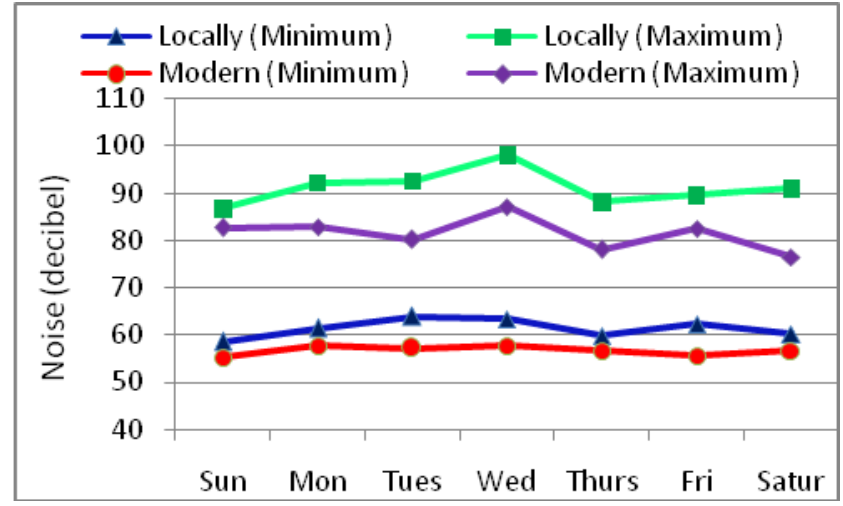

Figure 6: The Noise Levels (Max. and Min.) In Mid.

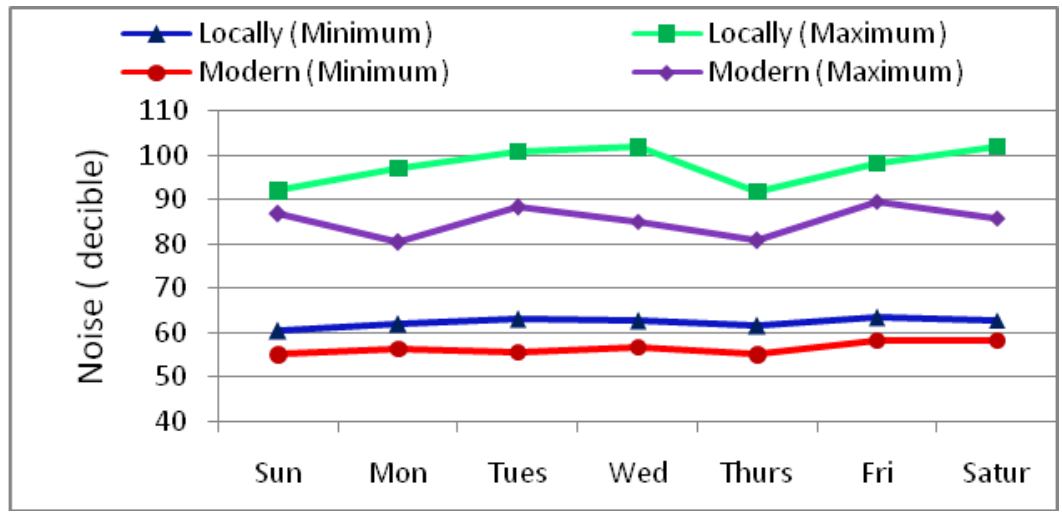

Figure 7: The Noise Levels (Max. and Min.) In North.

Table 2: The readings of Maximum and Minimum noise level in (dB).

\begin{tabular}{|c|c|c|c|c|c|c|c|c|c|c|c|c|}
\hline \multicolumn{6}{|c|}{ MIN. } & \multicolumn{6}{|c|}{ MAX. } & \multirow{3}{*}{ Days } \\
\hline \multicolumn{3}{|c|}{ Modern } & \multicolumn{3}{|c|}{ Local } & \multicolumn{3}{|c|}{ Modern } & \multicolumn{3}{|c|}{ Local } & \\
\hline South & Mid & North & South & Mid & North & South & Mid & North & South & Mid & North & \\
\hline 55.2 & 55.6 & 55.1 & 58.5 & 64.5 & 60.4 & 82.7 & 90.9 & 86.9 & 86.7 & 86.5 & 92.2 & Sun \\
\hline 57.6 & 56.3 & 56.5 & 61.3 & 63.4 & 61.9 & 82.8 & 83.5 & 80.4 & 92.3 & 91.6 & 97.3 & Mon \\
\hline 57.1 & 55.3 & 55.7 & 63.8 & 71.3 & 63 & 80.1 & 91.1 & 88.3 & 92.5 & 93.3 & 101 & Tues \\
\hline 57.7 & 55.2 & 56.8 & 63.4 & 71.2 & 62.7 & 87.1 & 93.7 & 85.1 & 98.1 & 95.1 & 102 & Wed \\
\hline 56.6 & 56.1 & 55.1 & 59.7 & 70.1 & 61.6 & 78 & 83.2 & 80.8 & 88.2 & 96.1 & 92 & Thurs \\
\hline 55.6 & 58.4 & 58.4 & 62.3 & 68.5 & 63.4 & 82.5 & 87.6 & 89.6 & 89.6 & 98.6 & 98.4 & Fri \\
\hline 56.6 & 57.9 & 58.3 & 60.2 & 69.4 & 62.9 & 76.4 & 92.8 & 86 & 91 & 90.3 & 102.2 & Satur \\
\hline
\end{tabular}

The results of first questionnaire were included the healthy and psychological impacts for the vendors where the harm ratio of them in Local and Modern markets with hypertension equal to $(62 \%, 4 \%)$, annoying $(100 \%, 32 \%)$, headache $(74 \%, 32 \%)$, nervous $(57 \%, 34 \%)$, boredom $(89 \%, 46 \%)$, Weakness of focus $(72 \%, 36 \%)$, nausea $(51 \%, 12 \%)$, mood fluctuation $(38 \%, 40 \%)$, Sleep disorder $(60 \%, 30 \%)$, the desire to quarrel with client $(53 \%, 14 \%)$ and hear losing $(23.4 \%, 4 \%)$ respectively. Figure (8) and table (3) explain the result of harm ratio of the vendors. 


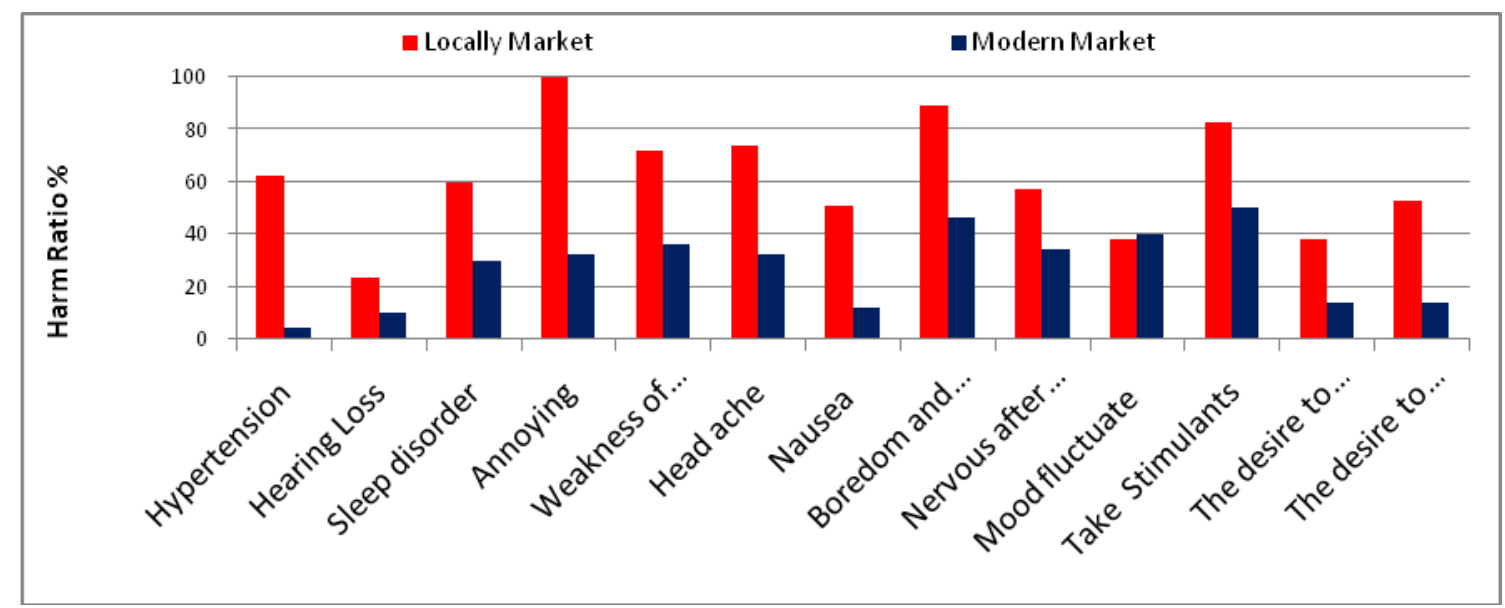

Figure 8: Ratio of Healthy and Psychological Harm .

Table 3: Ratio of Healthy and Psychological Harm.

\begin{tabular}{|c|c|c|}
\hline $\begin{array}{c}\text { Healthy and Psychological } \\
\text { Harm } \%\end{array}$ & QUESTION \\
\hline $\begin{array}{c}\text { Modern } \\
\text { Market }\end{array}$ & $\begin{array}{c}\text { Local } \\
\text { Market }\end{array}$ & Hypertension \\
\hline 4 & 62 & Hearing Loss \\
\hline 10 & 23.4 & Sleep disorder \\
\hline 30 & 60 & Annoying \\
\hline 32 & 100 & Heakness of focus \\
\hline 36 & 72 & Nausea \\
\hline 32 & 74 & Boredom and leaving work \\
\hline 12 & 51 & Nervous after work at home \\
\hline 46 & 89 & Mood fluctuate \\
\hline 34 & 57 & Take Stimulants \\
\hline 40 & 38 & The desire to quarrel with neighboring \\
\hline 50 & 83 & The desire to quarrel with clients \\
\hline 14 & 38 & \\
\hline 14 & 53 & \\
\hline & &
\end{tabular}

The results of second questionnaire represent the shoppers by choosing twelve persons who stayed two hours in each market to investigate the psychological effects on them. The results of questionnaire indicate that the harm ratio of them in Local and Modern markets with annoying equal to $(92 \%, 17 \%)$, headache $(58 \%, 25 \%)$, nervous $(25 \%, 25 \%)$, boredom $(33 \%, 25 \%)$, Weakness of focus $(58 \%, 42 \%)$, nausea $(67 \%, 58 \%)$. Figure (9) and Table (4) explain the comparison between the result of harm ratio of the shoppers in modern and local markets. 


\section{AL-QADISIYAH JOURNAL FOR ENGINEERING SCIENCES}

Vol. 10, No. 4

ISSN: 1998-4456

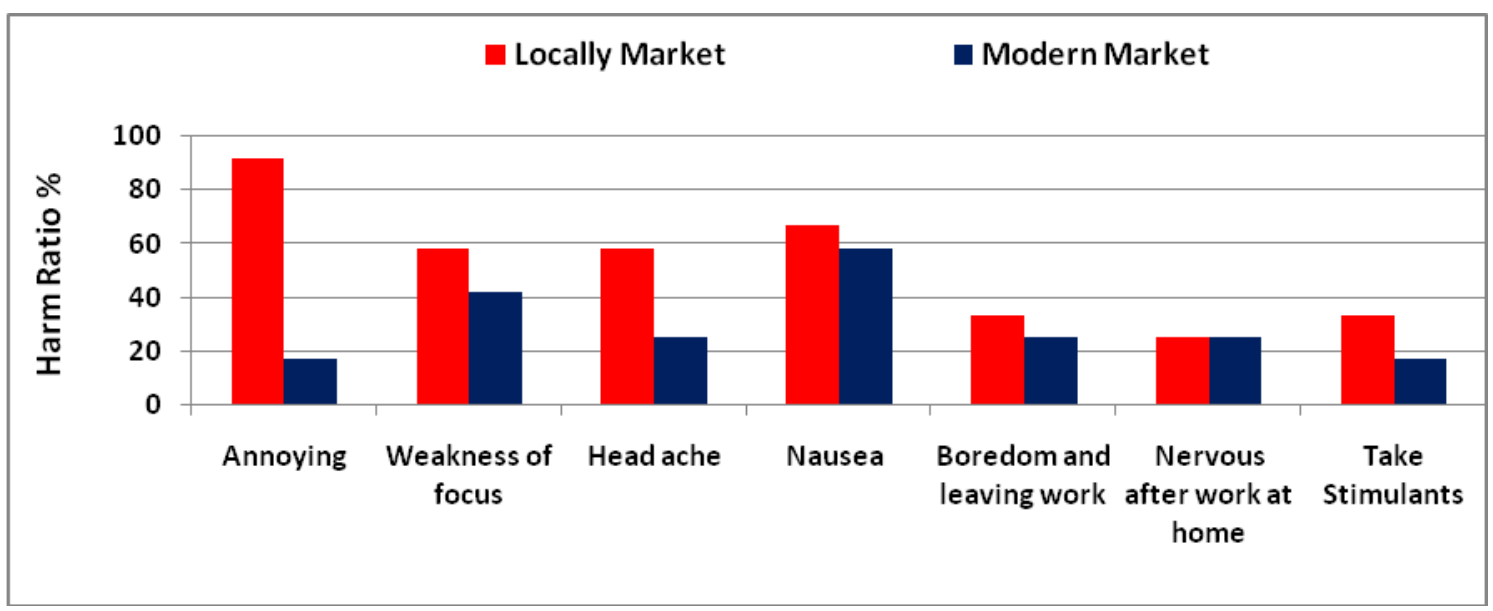

Figure 9: Ratio of Psychological Harm.

Table 4: Ratio of Psychological harm.

\begin{tabular}{|c|c|c|}
\hline \multicolumn{2}{|c|}{$\begin{array}{c}\text { Healthy and Psychological } \\
\text { harm } \%\end{array}$} & \multirow{2}{*}{ Questions } \\
\cline { 1 - 2 } Modern Market & Local Market & \\
\hline 17 & 92 & Annoying \\
\hline 42 & 58 & Weakness of focus \\
\hline 25 & 58 & Head ache \\
\hline 58 & 67 & Nausea \\
\hline 25 & 33 & $\begin{array}{c}\text { Boredom and } \\
\text { leaving shopping }\end{array}$ \\
\hline 25 & 25 & Nervous \\
\hline 17 & 33 & Take Stimulants \\
\hline
\end{tabular}

\section{DISCUSSION}

From the results, it can be observed that the noise level in Local market is higher than the noise level in modern market where in Local the noise in (Leq) ranged (70.5 to 85.6)dB while in Modern market ranged (62.6 to 70.2$) \mathrm{dB}$, this high noise which also higher than Iraqi standard (65) dB belongs to the using of the sound amplifiers in Local market which are not used in modern market.

Because the high noise in Local market, most of the vendors have suffered from healthy and psychological harm where the harm ratio in Local market is higher than Modern market. More than that, the annoying level in Local market reached up to $100 \%$ but the hearing loss in Local markets is $(23.4 \%$ ) and very low in Modern market which is about (10\%). Never the less, the noise level in Modern market cannot affect population (vendors or shoppers). The second questionnaire which represent the shoppers showed that the psychological effects in Local market are higher than the ones in Modern market especially annoying which was $(92 \%, 17 \%)$ respectively. But the harms ratio of the head ache, nausea, boredom and leaving shopping, nervous and weakness of focus were equal in both markets. 


\section{CONCLUSIONS}

- The sound amplifiers were the essential cause in height the noise level in Local markets.

- The noise level high than $70 \mathrm{~dB}$ cause healthy and psychological effects for the vendors.

- The noise level with $60 \mathrm{~dB}$ cannot affect population (vendors or shoppers).

\section{REFERENCES}

1. N. Garga, A. Kumarc, P.K. Sainid and S. Majib , "A retrospective view of ambient noise standards in India: Status and proposed revisions", Institute of Noise Control Engineering India, 2015.

2. Mirsaeed Attarchi, Faezeh Dehghan, Farnaz Safakhah, Marzieh Nojomi and Saber Mohammadi ," Effect of Exposure to Occupational Noise andShift Working on Blood Pressure in Rubber Manufacturing Company Workers" National Institute of Occupational Safety and Health,Iran,2012.

3. Shubhang Mishra and Dr. V. K. Sukhwani , "Changing Paradigm Of Industrial Noise Control: A Review" Asian Journal of Engineering Research, ISSN-2319-2100,India ,2013.

4. Deborah Imel Nelson, Robert Y. Nelson, Marisol Concha-Barrientos, Marilyn Fingerhut , "The global burden of occupational noise-induced hearing loss" the American Journal of Industrial Medicine, U.S.A, 2005.

5. Gayathri .K, A. Amutha Jaisheeba and R. Sornaraj ," Physical and Cardiovascular Implications of Noise Pollution prevailed in Thoothukudi the Industrial City, Tamilnadu, India". International Journal of ChemTech Research, ISSN : 0974-4290, India,2012.

6. Sameer Kumar, Gaurav Kumar, Kunal Gupta and Rajeev Kumar Mishra ," Traffic Noise Analysis at Road Side Hospitals during Peak Hour Traffic Flow" Innovative Energy Technology Systems And Environmental Concerns: A Sustainable Approach :ISBN: 978-93-84144-81-4, India, 2014.

7. Lee JH, Kang W, Yaang S, Choy N, Lee C, "Cohort study for the effect of chronic noise exposure on blood pressure among male workers in Busan, Korea". Am J Ind Med 52, 509-17.,(2009).

8. Abu Hamda ,Marwan Hamdi Said, "Effects of Noise Exposure on Blood Pressure and Pulse Rate of Employees in Intensive Care Units in Gaza Strip-Palestine" M.Sc. Thesis, Islamic University of Gaza, The Islamic University - Gaza- Palestine,2013.

9. Janna, Hussein , " Noise levels Assessment in Selected Places in Al-Diwaniyah City, Iraq" Al-Qadisiyah Journal For Engineering Sciences, Iraq ,2016. 